\title{
Влияние температуры измерения на люминесцентные свойства (113) дефектов в кремнии, имплантированном ионами кислорода
}

\author{
(C) Н.А. Соболев ${ }^{1}$, А.Е. Калядин ${ }^{1}$, Е.И. Шек ${ }^{1}$, К.Ф. Штельмах ${ }^{1,2}$ \\ ${ }^{1}$ Физико-технический институт им. А.Ф. Иоффе Российской академии наук, \\ 194021 Санкт-Петербург, Россия \\ ${ }^{2}$ Санкт-Петербургский политехнический университет Петра Великого, \\ 195251 Санкт-Петербург, Россия \\ E-mail: nick@sobolev.ioffe.rssi.ru
}

(Получена 20 февраля 2017 г. Принята к печати 1 марта 2017 г.)

Исследовано влияние температуры измерения в диапазоне 5-130K на спектры ФЛ (113) дефектов в кремнии, имплантированном ионами кислорода с энергией 350 кэВ и дозой $3.7 \cdot 10^{14} \mathrm{~cm}^{-2}$ и отожженном при $700^{\circ} \mathrm{C}$ в течение 1 ч в хлорсодержащей атмосфере. Температурная зависимость интенсивности линии характеризуется участками возгорания интенсивности с энергией 23.1 мэВ и гашения интенсивности с энергиями 41.9 и 178.3 мэВ. С ростом температуры линии сдвигаются в длинноволновую сторону, а их полуширина увеличивается.

DOI: $10.21883 /$ FTP.2017.09.44880.8561

\section{1. Введение}

В настоящее время отсутствуют светодиоды на длину волны 1300-1400 нм на основе монокристаллического кремния. Относительно недавно было обнаружено, что образование так называемых (113) дефектов [1], формирующихся из собственных межузельных атомов кремния после имплантации ионов $\mathrm{Si}$ с дозами $10^{13}-10^{14} \mathrm{~cm}^{-2}$ и последующего отжига в инертной атмосфере при температурах $600-750^{\circ} \mathrm{C}$, приводит к появлению линии фотолюминесценции (ФЛ) с длиной волны $\sim 1370$ нм [1-5]. Наблюдавшаяся корреляция во времени между появлением (113) дефектов и линии 1370 нм, выявляемых с помощью методов высокоразрешающей электронной микроскопии (HREM) и ФЛ соответственно, подтвердила, что эта линия принадлежит центру, образующемуся из собственных междоузлий в поле напряжений (113) дефекта. Недавно нами было установлено, что имплантация ионов кислорода и последующий отжиг в хлорсодержащей атмосфере при $700^{\circ} \mathrm{C}$ также сопровождаются образованием линии люминесценции (113) дефектов [6]. В работе были найдены оптимальные технологические условия (доза имплантации и длительность отжига) для достижения максимальной интенсивности ФЛ (113) дефектов. В настоящей работе исследованы зависимости основных параметров линии ФЛ (113) дефектов (интенсивности, положения максимума линии и ее полуширины) от температуры измерения в образцах кремния, имплантированных ионами кислорода.

\section{2. Экспериментальные условия}

Исследованные образцы представляли собой $p^{+}-n$ структуры на основе пластин $n-\mathrm{Cz}-\mathrm{Si}(100)$ с удельным сопротивлением $4.5 \mathrm{OM} \cdot \mathrm{cm}$, в которых методом диффузии примеси бора из газовой фазы формировался $p^{+}-n$-переход [6]. Со стороны $p^{+}-n$-перехода при комнатной температуре имплантировались ионы кислорода с энергией 350 кэВ и неаморфизующей дозой $3.7 \cdot 10^{14} \mathrm{~cm}^{-2}$. Проецированная длина пробега ионов $\mathrm{O}^{+}\left(R_{\mathrm{P}}\right)$, рассчитанная с помощью программы SRIM [7], составляла 790 нм. Таким образом, основная часть ионов кислорода вводилась глубже $p^{+}-n$-перехода. Последующий отжиг, в процессе которого происходили перестройка структурных дефектов и формирование люминесцентных центров, проводился при температуре $700^{\circ} \mathrm{C}$ в течение 1ч в хлорсодержащей атмосфере (XCA), которая представляла собой поток кислорода, насыщенный парами четыреххлористого углерода с молярной концентрацией $1 \%$. ФЛ возбуждалась твердотельным лазером на длине волны 532 нм и мощностью 56 мВТ и регистрировалась в области длин волн 1000-1650 нм при температурах 4.2-140 K с помощью автоматизированного монохроматора МДР-23 и InGaAs-фотоприемника, работающего при комнатной температуре. Разрешение установки составляло 7 нм. Образец помещался в криостат, который поддерживал температуру с точностью $\pm 0.2 \mathrm{~K}$. Параметры линии ФЛ (113) дефектов (интенсивность, положение максимума и полуширина) определялись путем их аппроксимации кривыми Гаусса.

\section{3. Экспериментальные результаты и их обсуждение}

На рис. 1 приведены спектры ФЛ исследуемых образцов при разных температурах измерения в диапазоне 1300-1420 нм. Приведенные линии обусловлены образованием (113) дефектов [2-6]. Эти линии доминируют в спектрах. Кроме них в спектрах ФЛ в области $1000-1650$ нм также присутствуют линии с длинами волн 1130, 1200, 1237 и 1467 нм, интенсивность которых существенно ниже, и в данной работе не рассматриваются. Характерной особенностью (113) линий является наличие у них асимметричного хвоста со стороны меньших длин волн. 
Как видно из рис. 1 , интенсивность линии люминесценции (113) дефектов с ростом температуры измерения до $35 \mathrm{~K}$ возрастает, а при дальнейшем росте температуры уменьшается и регистрируется при $130 \mathrm{~K}$. На рис. 2 приведены экспериментальные значения (кружки) максимума интенсивности линии ФЛ (113) дефекта в зависимости от обратной температуры. Полученная зависимость хорошо описывается формулой [8]:

$$
\begin{aligned}
I(T) & =I(0)\{1+C /[1+A \exp (-W / k T)]\}^{-1} \\
& \times\left[1+B_{1} \exp \left(-E_{1} / k T\right)+B_{2} \exp \left(-E_{2} / k T\right]^{-1},\right.
\end{aligned}
$$

где $W, E_{1}$ и $E_{2}-$ энергии возгорания и гашения люминесценции соответственно, $C$ - величина, включающая

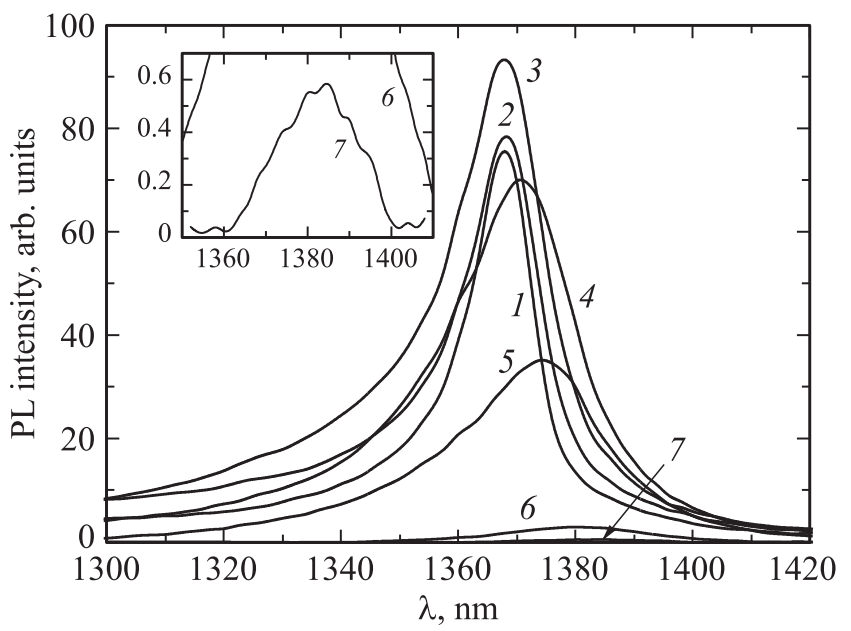

Рис. 1. Спектры ФЛ $\mathrm{Si}: \mathrm{O}$ образцов, имплантированных ионами кислорода с энергией 350 кэВ и дозой $3.7 \cdot 10^{14} \mathrm{~cm}^{-2}$ и отожженных при $700^{\circ} \mathrm{C}$ в течение 1 ч в ХCA, при температурах измерения, $\mathrm{K}: 1-5,2-20,3-35,4-70,5-80,6-120$ и 7 - 130. На вставке показаны спектры ФЛ при 120 и $130 \mathrm{~K}$. Мощность накачки 56 мВт.

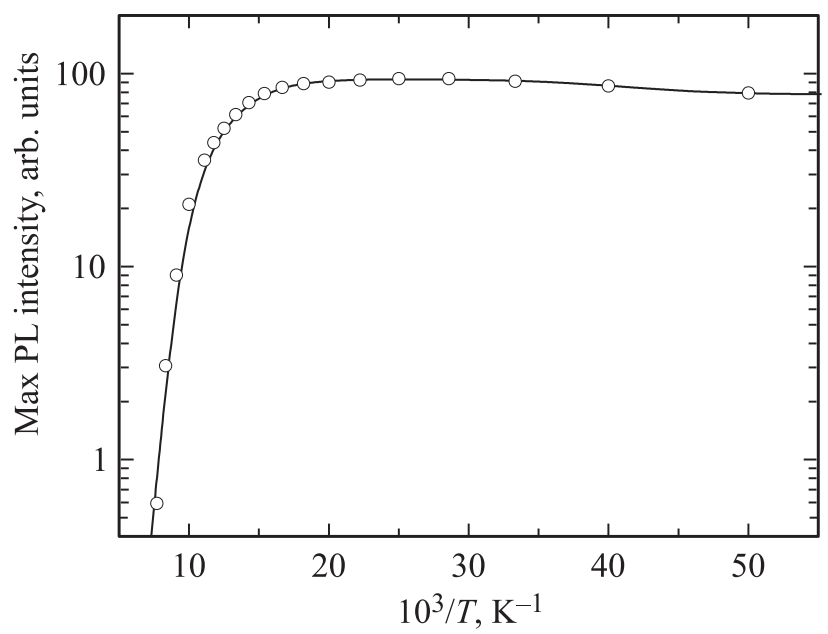

Рис. 2. Зависимость максимума интенсивности линии ФЛ (113) дефектов от обратной температуры: кружки - экспериментальные значения, сплошная линия - аппроксимирующая кривая.

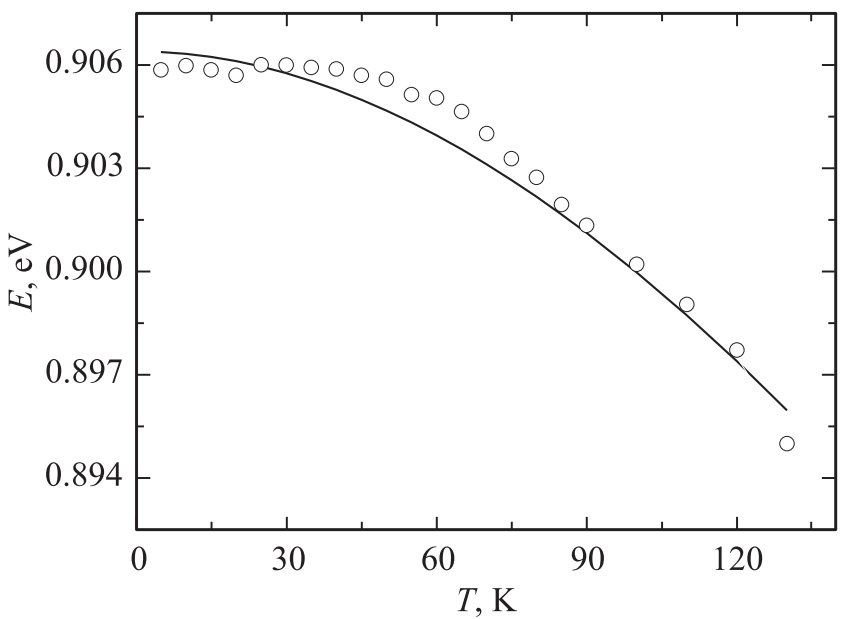

Рис. 3. Температурная зависимость положения максимума линии ФЛ (113) дефектов (кружки). Сплошная кривая описывается формулой (3).

отношение сечений захвата экситона на люминесцентные центры и ловушки, $A$ и $B-$ константы связи для данного центра, $k$ - постоянная Больцмана. Аппроксимирующая кривая (сплошная линия) приведена на рис. 2. Константы в формуле (1) равны $A=62000, C=0.20$, $B_{1}=333$ и $B_{2}=7$. При низких температурах экситоны захватываются на мелкие центры. При повышении температуры они освобождаются, диффундируют, а затем происходит их захват и последующая излучательная рекомбинация на люминесцентном центре (113) дефекта. В результате с ростом температуры наблюдается возгорание интенсивности ФЛ линии (113) дефектов, которое характеризуется энергией возгорания интенсивности $Ф Л ~ W=23.1$ мэВ. При дальнейшем повышении температуры наблюдается гашение интенсивности ФЛ (113) центра, которое характеризуется двумя энергиями $E_{1}=41.9$ и $E_{2}=178.3$ мэВ. Гашение интенсивности ФЛ обусловлено деактивацией возбужденного состояния (113) центра и(или) появлением каналов безызлучательной рекомбинации. Как правило, этот процесс представляет собой многофононную безызлучательную рекомбинацию. Насколько нам известно, температурная зависимость интенсивности люминесценции линии (113) дефектов нами исследовалась впервые.

На рис. 3 приведены экспериментальные значения положений максимумов линии ФЛ (113) дефектов от температуры (кружки). При температуре $78 \mathrm{~K}$ максимум линии находится при 1373 нм (0.903 эВ), что соответствует значению, полученному в работе [6]. Видно, что с ростом температуры наблюдается сдвиг максимума линии люминесценции в длинноволновую сторону. Температурная зависимость ширины запрещенной зоны кремния (в эВ) описывается формулой [9]

$$
E_{g}=1.17-4.73 \cdot 10^{-4} \cdot T^{2} /(T+636),
$$

где $T$ - температура в градусах К. Как показал анализ, экспериментальная температурная зависимость 


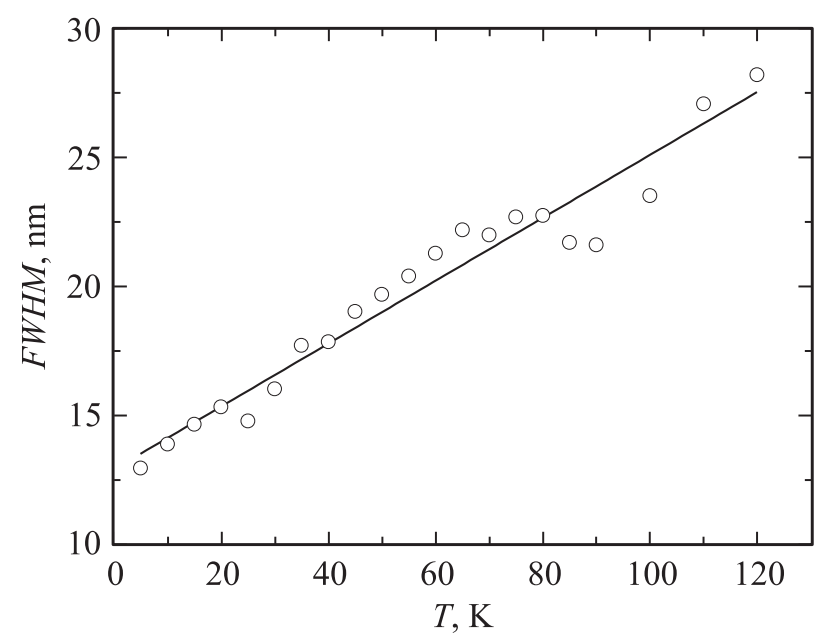

Рис. 4. Температурная зависимость полуширины линии люминесценции (113) дефектов (кружки). Сплошная кривая описывается формулой (4).

максимумов линии ФЛ (113) дефектов $\left(E_{111}\right)$ достаточно хорошо описывается зависимостью

$$
\begin{aligned}
E_{111} & =E_{g}-0.264 \\
& =0.906-4.73 \cdot 10^{-4} \cdot T^{2} /(T+636),
\end{aligned}
$$

которая отличается от формулы (2) уменьшением значений энергии на величину 0.264 эВ. Это означает, что с ростом температуры энергетическое положение (113) дефектов смещается параллельно уменьшению ширины запрещенной зоны кремния. Отметим, что ранее для линий дислокационной люминесценции $D 1$ и $D 2$ также наблюдалось уменьшение значений их энергетических положений синхронно с шириной запрещенной зоны кремния при уменьшении температуры [10].

На рис. 4 приведены экспериментальные значения (кружки) полной ширины линии на половине высоты $(F W H M)$ люминесценции (113) дефектов при разных температурах. С ростом температуры полуширина увеличивается. Измеренная зависимость (в нм) хорошо аппроксимируется линейной зависимостью:

$$
F W H M=a T+b .
$$

Константы в формуле (4) равны $a=0.12 \mathrm{Hм} / \mathrm{K}$ и $b=12.9$ нм. Ранее увеличение полуширины линий люминесценции с ростом температуры измерения наблюдалось для линий дислокационной люминесценции $D 1$ и $D 2$, также сформированных с участием собственных межузельных атомов кремния [10].

\section{4. Заключение}

В имплантированном ионами кислорода кремнии впервые исследовано влияние температуры измерения на параметры линии ФЛ (интенсивность, положение и полуширина) (113) дефектов. Интенсивность линии люминесценции (113) дефектов с ростом температуры измерения до $35 \mathrm{~K}$ возрастает, а при дальнейшем росте температуры уменьшается и регистрируется при $130 \mathrm{~K}$. Увеличение температуры измерения сопровождается смещением линии в длинноволновую сторону и увеличением ее полуширины. Полученные результаты дополняют и развивают существующие представления о люминесцентных свойствах (113) дефектов.

\section{Список литературы}

[1] S. Takeda. Jpn. J. Appl. Phys., 30, L639 (1991).

[2] S. Coffa, S. Libertino, C. Spinella. Appl. Phys. Lett., 76, 321 (2000).

[3] P.K. Giri. Semicond. Sci. Technol., 20, 638 (2005).

[4] Yang Yu, Wang Chong, Yang Rui-Dong, Li Liang, Xiong Fei, Bao Ji-Ming. Chinese Phys. B, 18, 4906 (2009).

[5] Yu Yang, Jiming Bao, Chong Wang, Michael J. Aziz. J. Appl. Phys., 107, 123109 (2010).

[6] Н.А. Соболев, А.Е. Калядин, П.Н. Аруев, В.В. Забродский, Е.И. Шек, К.Ф. Штельмах, К.В. Карабешкин. ФТТ, 58, 2411 (2016).

[7] J.F. Ziegler, M.D. Ziegler, J.P. Biersack. Nucl. Instrum. Meth. B, 268, 1818 (2010).

[8] G. Davies. Phys. Reports, 176, 83 (1989).

[9] R. Braunstein, A.R. Moor, F. Herman. Phys. Rev., 109, 695 (1958).

[10] Н.А. Соболев. ФТП, 44, 3 (2010).

Редактор А.Н. Смирнов

\section{Influence of the measurement temperature on luminescence properties of the (113) defects in oxygen-implanted silicon}

\author{
N.A. Sobolev ${ }^{1}$, A.E. Kalyadin ${ }^{1}$, E.I. Shek ${ }^{1}$, \\ K.F. Shtel'makh ${ }^{1,2}$ \\ ${ }^{1}$ loffe Institute, \\ 194021 St. Petersburg, Russia \\ 2 Peter the Great Saint Petersburg \\ Polytekhnic University, \\ 195251 St. Petersburg, Russia
}

Abstract Influence of a measurement temperature over a range of $5-130 \mathrm{~K}$ on the photoluminescence spectra of the (113) defects is studied in $\mathrm{Si}$ implanted by oxygen ions with an energy of $350 \mathrm{keV}$ at doses of $1.7 \cdot 10^{13}-1.7 \cdot 10^{15} \mathrm{~cm}^{-2}$ and annealed at temperature of $700^{\circ} \mathrm{C}$ for $0.5-2 \mathrm{~h}$ in a chlorine-containing atmosphere. The temperature dependence of the line intensity is characterized by the areas of an intensity enhancing with an energy of $23.1 \mathrm{meV}$ and of an intensity quenching with the energies of 41.9 and $178.3 \mathrm{meV}$. With increasing temperature, the lines move to the long-wave side and their half width increases. 